\title{
Kayvan Shokrollahi, Lain S. Whitaker, Foad Nahai: Flaps: Practical reconstructive surgery
}

\section{Thieme Verlag New York, Stuttgart, Delhi, Rio de Janeiro, 2017, 711 pp.; num III. Hardcover, 253.37€, ISBN: 978-1-60406-715-6}

\author{
Pierre Kehr ${ }^{1}$. Alain G. Graftiaux ${ }^{1}$
}

Received: 31 October 2017 / Accepted: 17 November 2017 / Published online: 7 December 2017

(c) Springer-Verlag France SAS, part of Springer Nature 2017

The purpose of this book is not to be encyclopedic but to describe the scraps most used in rebuilding surgery. The goal is to describe them step by step in order to make their realization easy. It is about a richly illustrated book multi-authors from which the various chapters are built on the same principle. Complementary videos are available on the site of the editor and supplement the description of the book usefully.

The first part gathers the general information concerning the basic principles, plannings, the techniques in particular microsurgical, and the indications.

The second part relates to the various scraps, some will be extremely useful for the orthopedic surgeon in the gestures of rebuilding for the level of the hand and the upper limb and the lower extremity.
The last part relates to the scraps more complex in particular composite (with the muscles bones for example).

This book extremely well fact will interest the students but also the experienced surgeons who treat complex pathologies, of traumatic or tumoral rebuilding for example, requiring a cutaneous cover.

\section{Compliance with ethical standards}

Conflict of interest The authors declare that they have no conflict of interest.
Pierre Kehr

pierre.kehr@gmail.com

1 Strasbourg, France 